\section{RMD Open}

Rheumatic \&

Musculoskeletal Diseases

\title{
Pharmacodynamic and pharmacokinetic effects and safety of verinurad in combination with allopurinol in adults with gout: a phase IIa, open-label study
}

To cite: Fleischmann $\mathrm{R}$, Winkle P, Miner JN, et al. Pharmacodynamic and pharmacokinetic effects and safety of verinurad in combination with allopurinol in adults with gout: a phase Ila, open-label study. RMD Open 2018;4:e000584. doi:10.1136/ rmdopen-2017-000584

- Prepublication history and additional material for this paper are available online. To view these files, please visit the journal online (http://dx.doi. org/10.1136/rmdopen-2017000584).

Received 21 September 2017 Revised 22 December 2017 Accepted 29 December 2017

Check for updates

${ }^{1}$ Metroplex Clinical Research Center, University of Texas, SW Medical Center, Dallas, Texas, USA

${ }^{2}$ Anaheim Clinical Trials, Anaheim, California, USA ${ }^{3}$ Ardea Biosciences, San Diego, California, USA

${ }^{4}$ AstraZeneca LP, Gaithersburg, Maryland, USA

${ }^{5}$ QPS MRA (Miami Clinical

Research), Miami, Florida, USA

Correspondence to

Dr Roy Fleischmann;

rfleischmann@arthdocs.com

\section{ABSTRACT}

Objectives Verinurad (RDEA3170) is a high affinity, selective uric acid transporter (URAT1) inhibitor indevelopment for treating gout and asymptomatic hyperuricaemia. This phase lla study evaluated the pharmacodynamics, pharmacokinetics and safety of verinurad combined with allopurinol versus allopurinol alone in adults with gout.

Methods Forty-one subjects were randomised into two cohorts of verinurad (2.5-20 mg) plus allopurinol (300 mg once daily) versus allopurinol $300 \mathrm{mg}$ once daily, $600 \mathrm{mg}$ once daily or $300 \mathrm{mg}$ twice daily alone. Each treatment period was 7 days. Serial plasma/serum and urine samples were assayed for verinurad, allopurinol, oxypurinol and uric acid.

Results Serum pharmacodynamic data pooled across cohorts demonstrated maximum per cent decreases in serum urate (sUA) from baseline $\left(\mathrm{E}_{\max }\right)$ at $7-12$ hours after verinurad plus allopurinol treatment. Combination treatment decreased sUA in dose-dependent manner: least-squares means $\mathrm{E}_{\max }$ was $47 \%, 59 \%, 60 \%, 67 \%$, $68 \%$ and $74 \%$ for verinurad doses $2.5,5,7.5,10,15$ and $20 \mathrm{mg}$ plus allopurinol $300 \mathrm{mg}$ once daily, versus $40 \%$, $54 \%$ and $54 \%$ for allopurinol $300 \mathrm{mg}$ once daily, $600 \mathrm{mg}$ once daily and $300 \mathrm{mg}$ twice daily. Verinurad had no effect on allopurinol plasma pharmacokinetics, but decreased oxypurinol $C_{\text {max }}$ by $19.0 \%-32.4 \%$ and area under the plasma concentration-time curve from time zero to the last measurable time point by $20.8 \%-39.2 \%$. Verinurad plus allopurinol was well tolerated with no serious adverse events (AEs), AE-related withdrawals or renal-related events. Laboratory values showed no clinically meaningful changes.

Conclusion Verinurad coadministered with allopurinol produced dose-dependent decreases in sUA. All dose combinations of verinurad and allopurinol were generally well tolerated. These data support continued investigation of oral verinurad in patients with gout.

Trial registration number NCT02498652.

\section{INTRODUCTION}

Gout is characterised by the deposition of monosodium urate crystals in the joints,

\section{Key messages}

What is already known about this subject?

- Many patients with gout do not achieve their serum urate (sUA)-lowering targets during treatment with a xanthine oxidase inhibitor (XOI), for example, allopurinol or febuxostat, alone.

- The pharmacodynamics, pharmacokinetics and safety of verinurad in combination with allopurinol $300 \mathrm{mg}$ once daily have not previously been investigated in subjects with gout in comparison with allopurinol $300 \mathrm{mg}$ once daily, $600 \mathrm{mg}$ once daily or $300 \mathrm{mg}$ twice daily alone.

What does this study add?

- Verinurad at doses of 2.5-20 mg in combination with allopurinol $300 \mathrm{mg}$ once daily produced dose-dependent lowering of sUA levels. Verinurad at doses $\geq 5 \mathrm{mg}$ in combination with allopurinol $300 \mathrm{mg}$ once daily produced greater sUA lowering than allopurinol $600 \mathrm{mg}$ once daily or $300 \mathrm{mg}$ twice daily alone.

- Allopurinol $600 \mathrm{mg}$ produced equivalent sUA lowering when administered once or twice daily.

How might this impact on clinical practice?

- If approved, verinurad in combination with an $\mathrm{XOI}$ may represent an effective treatment option in patients with gout who have an incomplete response to an $\mathrm{XOI}$ alone, providing a greater sUA lowering than dose escalation of $\mathrm{XOI}$.

tendons and other connective tissues, secondary to long-standing hyperuricaemia. ${ }^{1-3}$ Reducing the concentration of serum urate (sUA) below its saturation point leads, over time, to the dissolution of crystals and the alleviation of gout symptoms. ${ }^{45}$ To achieve this goal, patients typically require long-term urate-lowering therapy (ULT) in addition to lifestyle and dietary changes. 
Current ULTs can be grouped by their mechanism of sUA reduction: the xanthine oxidase inhibitors (XOIs) allopurinol and febuxostat reduce urate production, while the uricosuric agents probenecid, benzbromarone, sulfinpyrazone and lesinurad increase renal excretion of uric acid by inhibiting its reabsorption. ${ }^{3}$ Finally, the injectable uricases-for use in patients with severe tophaceous gout- enzymatically degrade uric acid to allantoin. ${ }^{6}$

Allopurinol is the most widely prescribed first-line ULT for gout. Dosing recommendations for allopurinol are to start at $\leq 100 \mathrm{mg} /$ day to reduce the risk of allopurinol hypersensitivity syndrome and to titrate in $100 \mathrm{mg}$ /day increments every 2-4 weeks while monitoring sUA to achieve and maintain a target sUA of $<6 \mathrm{mg} / \mathrm{dL}$ ( or $<5 \mathrm{mg}$ / $\mathrm{dL}$ in patients with severe gout symptoms) ${ }^{78}$ Allopurinol is approved at a daily dose up to $800 \mathrm{mg}$ (USA) or $900 \mathrm{mg}$ (Europe), although in practice few patients receive more than $300 \mathrm{mg},{ }^{9}$ in part due to physicians' concerns over the safety of higher doses. ${ }^{10}$ The majority of patients fail to achieve their target sUA on allopurinol monotherapy. ${ }^{9}{ }^{10}$ For these patients, guidelines recommend switching to febuxostat monotherapy or combining treatments with complementary mechanisms of action, such as an XOI with a uricosuric agent. ${ }^{57}$

Lesinurad is a uricosuric agent approved in combination with allopurinol or febuxostat for the treatment of hyperuricaemia associated with gout in patients failing to achieve target sUA on an XOI alone. ${ }^{11-13}$ In the phase III clinical development programme, treatment with lesinurad at $200 \mathrm{mg}$ and $400 \mathrm{mg}$ doses in combination with febuxostat resulted in more patients achieving target sUA and experiencing reduction in overall tophus area compared with febuxostat alone. ${ }^{12}$ Neither the lesinurad $200 \mathrm{mg}$ nor $400 \mathrm{mg}$ dose combinations significantly reduced gout flares versus febuxostat alone at 12 months; however, the $400 \mathrm{mg}$ combination did trend lower. The $400 \mathrm{mg}$ lesinurad dose was associated with increased renal adverse effects (compared with lesinurad $200 \mathrm{mg}$ plus febuxostat or febuxostat alone) and was neither submitted to, nor approved by, US and European regulatory agencies.

The clinical trial experience with ULTs demonstrates that more precipitous and increased lowering of sUA below target levels may lead to improved outcomes (eg, lower gout flare incidence, more rapid tophus area reduction). ${ }^{14-18}$

Verinurad, a next-generation uric acid transporter (URAT1) inhibitor, demonstrates high potency in inhibiting URAT $1 .{ }^{19}$ Verinurad at doses as low as $2.5 \mathrm{mg}$ produces significant sUA lowering in humans, ${ }^{20-22}$ and this significant dose-dependent reduction in sUA may lead to improved outcomes and medical benefits for patients with gout. As observed for other uricosurics, verinurad monotherapy has been associated with elevated concentrations of urinary uric acid and instances of serum creatinine ( $\mathrm{sCr}$ ) elevation..$^{20}$ XOIs, by contrast, are known to reduce urinary uric acid excretion by inhibiting urate production ${ }^{23}$ and the combination of an XOI with verinurad has been shown to maintain pretreatment levels of urinary uric acid excretion. ${ }^{24}$ Coadministration of an XOI with verinurad may therefore mitigate the renal effects of verinurad monotherapy, while lowering sUA to a greater extent than with either agent alone at the same dose.

Verinurad studies in healthy volunteers show that $\sim 64 \%$ of a single oral $10 \mathrm{mg}$ dose is absorbed, with a median time to maximum observed plasma concentration $\left(\mathrm{T}_{\max }\right)$ of 0.5 hours and a terminal half-life of 15 hours. ${ }^{25}$

The current study evaluated the pharmacodynamics (PD), pharmacokinetics (PK) and safety of multiple doses of verinurad in combination with allopurinol compared with allopurinol monotherapy in adults with gout (NCT02498652). The doses of allopurinol monotherapy investigated included $300 \mathrm{mg}$ once daily, $600 \mathrm{mg}$ once daily and $300 \mathrm{mg}$ twice a day. In addition to investigating dose combinations of verinurad with allopurinol, this study therefore provides a direct comparison of the PD of allopurinol $600 \mathrm{mg}$ when administered once or twice daily.

\section{METHODS}

\section{Subjects}

This phase IIa, randomised, open label, multicentre study investigated subjects with a diagnosis of gout according to American Rheumatism Association Criteria. ${ }^{26}$ Subjects were required to be aged $\geq 18$ and $\leq 75$ years with a body weight $\geq 50 \mathrm{~kg}$, body mass index (BMI) $\geq 18$ to $\leq 45 \mathrm{~kg} / \mathrm{m}^{2}$, sUA $\geq 8 \mathrm{mg} / \mathrm{dL}$ and estimated sCr clearance $\geq 60 \mathrm{~mL} / \mathrm{min}$ calculated by the Cockcroft-Gault formula using ideal body weight.

The study was conducted in compliance with Good Clinical Practice and the Declaration of Helsinki. Subjects provided informed consent to participate in the study. The study was performed from July to November 2015.

\section{Study design}

Two cohorts of subjects were randomised by incomplete block design to one of eight treatment sequences that included allopurinol ( $300 \mathrm{mg}$ once daily) in combination with varying verinurad doses (Cohort 1: $2.5-15 \mathrm{mg}$, Cohort 2: 5-20 mg) or allopurinol $300 \mathrm{mg}$ once daily, $600 \mathrm{mg}$ once daily or 300 twice daily alone. Randomisation used a centralised Interactive Web Response System that generated a unique randomisation number for each subject. Treatment sequences were randomised to avoid a 'sequence effect' (figure 1). Each treatment period was 7 days, which combined a period for washing out the previous treatment and for stabilising the new treatment.

Subjects on prior ULT were started on colchicine $0.6 \mathrm{mg}$ for gout flare prophylaxis at the beginning of ULT washout on approximately day -14 . Subjects not on ULT started colchicine on approximately day -7 . Verinurad and allopurinol $300 \mathrm{mg}$ once daily or $600 \mathrm{mg}$ once daily were administered approximately $30 \mathrm{~min}$ after a standardised breakfast (approximately $650 \mathrm{kcal}$ and 35\% 


\begin{tabular}{|c|c|c|c|c|c|}
\hline Duration & Days 1-7 & Days 8-14 & Days 15-21 & Days 22-28 & Days 29-35 \\
\hline \multicolumn{6}{|c|}{ COHORT 1, Treatment } \\
\hline Seq 1 & ALLO 300 & $\begin{array}{l}\text { VERU } 2.5 \\
\text { combo }\end{array}$ & $\begin{array}{l}\text { VERU } 15 \\
\text { combo }\end{array}$ & $\begin{array}{l}\text { VERU } 7.5 \\
\text { combo }\end{array}$ & ALLO 600 \\
\hline Seq 2 & $\begin{array}{c}\text { VERU } 7.5 \\
\text { combo }\end{array}$ & ALLO 300 & $\begin{array}{l}\text { VERU } 15 \\
\text { combo }\end{array}$ & $\begin{array}{l}\text { VERU } 2.5 \\
\text { combo }\end{array}$ & ALLO 600 \\
\hline Seq 3 & $\begin{array}{c}\text { VERU } 7.5 \\
\text { combo }\end{array}$ & $\begin{array}{l}\text { VERU } 2.5 \\
\text { combo }\end{array}$ & ALLO 300 & $\begin{array}{l}\text { VERU } 15 \\
\text { combo }\end{array}$ & ALLO 300 BID \\
\hline Seq 4 & $\begin{array}{c}\text { VERU } 7.5 \\
\text { combo }\end{array}$ & $\begin{array}{l}\text { VERU } 15 \\
\text { combo }\end{array}$ & $\begin{array}{l}\text { VERU } 2.5 \\
\text { combo }\end{array}$ & ALLO 300 & ALLO 300 BID \\
\hline \multicolumn{6}{|c|}{ COHORT 2, Treatment } \\
\hline Seq 5 & ALLO 300 & $\begin{array}{l}\text { VERU } 5 \\
\text { combo }\end{array}$ & $\begin{array}{c}\text { VERU } 20 \\
\text { combo }\end{array}$ & $\begin{array}{c}\text { VERU } 10 \\
\text { combo }\end{array}$ & ALLO 300 BID \\
\hline Seq 6 & $\begin{array}{l}\text { VERU } 10 \\
\text { combo }\end{array}$ & ALLO 300 & $\begin{array}{c}\text { VERU } 20 \\
\text { combo }\end{array}$ & $\begin{array}{l}\text { VERU } 5 \\
\text { combo }\end{array}$ & ALLO 300 BID \\
\hline Seq 7 & $\begin{array}{l}\text { VERU } 5 \\
\text { combo }\end{array}$ & $\begin{array}{l}\text { VERU } 10 \\
\text { combo }\end{array}$ & ALLO 300 & $\begin{array}{l}\text { VERU } 20 \\
\text { combo }\end{array}$ & ALLO 600 \\
\hline Seq 8 & $\begin{array}{l}\text { VERU } 10 \\
\text { combo }\end{array}$ & $\begin{array}{l}\text { VERU } 5 \\
\text { combo }\end{array}$ & $\begin{array}{c}\text { VERU } 20 \\
\text { combo }\end{array}$ & ALLO 300 & ALLO 600 \\
\hline
\end{tabular}

Figure 1 Study design. ALLO 300, allopurinol $300 \mathrm{mg}$ once daily; VERU×combo, verinurad×mg combination with ALLO $300 \mathrm{mg}$ once daily; ALLO 600, allopurinol $600 \mathrm{mg}$ once daily; ALLO 300 BID, allopurinol $300 \mathrm{mg}$ twice daily.

fat). For allopurinol $300 \mathrm{mg}$ BID, the second allopurinol dose was given in the evening after a meal, approximately 10 hours after the first dose.

\section{Blood and urine sampling}

Serum samples for PD analyses were collected at screening and at frequent preset intervals on baseline (day -1) and days 7, 14, 21, 28 and 35. Serial blood samples for PK analyses were collected on days 7, 14, 21, 28 and 35. Plasma was isolated from the blood by centrifugation. Urine samples (total catch) for PD and PK analyses were collected at 1 hour intervals rising to 2-hour or 10-hour intervals. Baseline sUA and $\mathrm{sCr}$ concentrations were assessed on day -2 .

On PD/PK urine collection days, subjects were instructed to drink $240 \mathrm{~mL}$ of water immediately on waking (within 2 hours predose) to maintain their urine output. Study medication was administered with another $240 \mathrm{~mL}$ of water. After dosing, subjects were instructed to drink $\sim 160 \mathrm{~mL}$ of water per hour for the next 12 hours with an additional $240 \mathrm{~mL}$ at 22 hours.

\section{Analytical methods}

Verinurad, allopurinol and oxypurinol concentrations in plasma and urine were measured by Ardea Biosciences (San Diego, California, USA). Plasma samples were extracted by protein precipitation and analytes quantified by high-performance liquid chromatography-mass spectrometry/mass spectrometry (LC-MS/MS) detection, while urine samples were prepared by dilution with water and quantified by high-performance LC-MS/ MS. $^{22} 24$
Assay performance information is included in the online Supplementary file 1 .

\section{End points and determinations}

All subjects who received at least one dose of verinurad or allopurinol with evaluable PD or PK data were included in the PD and PK populations. All subjects who received at least one dose of verinurad or allopurinol made up the safety population.

The primary study objective was an assessment of the multiple-dose PD of verinurad in combination with allopurinol compared with allopurinol alone. The PD of allopurinol $600 \mathrm{mg}$ once daily versus $300 \mathrm{mg}$ twice daily was additionally compared. Planned PD parameters included maximum per cent change in sUA from baseline $\left(\mathrm{E}_{\max }\right)$, mean time-matched per cent change in sUA from baseline (day -1$)$, rate of urinary uric acid excretion, renal clearance of uric acid and fractional excretion of uric acid for each 24-hour collection period.

For PD analyses, a mixed-effects model was used on $\mathrm{E}_{\max }$, with sequence and treatment as fixed effects, subject as a random effect and baseline value as a covariate. The least-squares means for each treatment group and between-treatment differences, along with 95\% CIs and $\mathrm{P}$ values were estimated for each cohort. All statistical testing was conducted at an alpha level of 0.05 . No adjustments were made for multiple comparisons. For summary statistics, data were pooled across cohorts according to allopurinol treatment. PD data were collected by Covance Central Laboratory Services (Indianapolis, Indiana, USA) and analyses were performed using SAS V.9.3 or later. 
PK assessments investigated the dose proportionality of verinurad $2.5-20 \mathrm{mg}$ in the presence of allopurinol $300 \mathrm{mg}$ and the comparative PK of allopurinol $300 \mathrm{mg}$ twice daily versus $600 \mathrm{mg}$ once daily, using a power model in Phoenix WinNonlin software V.6.3 (Pharsight Corporation, Mountain View, California, USA). PK parameters for verinurad, allopurinol and oxypurinol (the main metabolite of allopurinol) included maximum observed plasma concentration $\left(\mathrm{C}_{\max }\right), \mathrm{T}_{\max }$, area under the plasma concentration-time curve from time zero to 24 hours postdose $\left(\mathrm{AUC}_{0-24}\right)$ and from time zero to the last measurable time point $\left(\mathrm{AUC}_{\text {last }}\right)$, plasma terminal half-life $\left(\mathrm{t}_{1 / 2}\right)$, amount excreted in urine $\left(\mathrm{Ae}_{0-24}\right)$, fraction excreted in urine as unchanged drug or metabolite $\left(\mathrm{fe}_{0-24}\right)$ and renal clearance from time zero to 24 hours postdose $\left(\mathrm{CL}_{\mathrm{R} 0-24}\right)$.

For PK analyses, a mixed-effects model was used on $\mathrm{AUC}_{\text {last }}$ or $\mathrm{AUC}_{0-24}, \mathrm{C}_{\max }$ and $\mathrm{CL}_{\mathrm{R} 0-24 \text {, with treatment (allo- }}$ purinol in the presence of verinurad vs allopurinol alone) as a fixed effect and subject as a random effect. Geometric mean $(90 \%$ CI $)$ PK parameters of allopurinol and oxypurinol are presented in the presence of varying verinurad doses versus allopurinol $300 \mathrm{mg}$ once daily alone. Additionally, a fixed-effect analysis of variance model was used to compare the $\mathrm{C}_{\max }$ and $\mathrm{AUC}_{0-24}$ of allopurinol and oxypurinol between the two parallel allopurinol dose groups (allopurinol $600 \mathrm{mg}$ once daily vs $300 \mathrm{mg}$ twice daily). In the twice daily regimen, $\mathrm{AUC}_{0-24}$ values for allopurinol or oxypurinol were extrapolated based on concentration profiles following the morning dose (estimated as $2 \times \mathrm{AUC}_{0-12}$ ). PK analyses were conducted by Ardea Biosciences, using Phoenix WinNonlin V.6.3.

Subjects were monitored for safety throughout the study and at follow-up on day $49( \pm 2)$. Safety assessments included adverse events (AEs) coded according to the Medical Dictionary for Regulatory Activities (V.17.0), clinical laboratory evaluations, vital signs, electrocardiograms and physical examinations. AEs were defined as serious if they resulted in death, were life threatening, required hospitalisation or prolongation of existing hospitalisation or caused persistent or significant disability/incapacity. Any renal serious AEs were to be reviewed by a Renal Events Adjudication Committee appointed by the study sponsor during conduct of the verinurad clinical studies. Any haematology, chemistry or urinalysis abnormalities considered clinically relevant were to be assigned a severity rating by the investigator, based on Rheumatology Common Toxicity Criteria V.2.0, 2007. ${ }^{27}$ Safety data are summarised by descriptive statistics using SAS V.9.3 or later.

\section{RESULTS}

Subjects

A total of 41 subjects were randomised to treatment in one of the two cohorts ( $\mathrm{n}=20$, Cohort $1 ; \mathrm{n}=21$, Cohort 2$)$. Forty subjects completed the study as per protocol. One randomised subject in Cohort 2 was withdrawn because of non-compliance/protocol violation.
Table 1 Demographic characteristics and serum urate levels

\begin{tabular}{|c|c|c|c|}
\hline & $\begin{array}{l}\text { Cohort } 1 \\
(n=20)\end{array}$ & $\begin{array}{l}\text { Cohort } 2 \\
(n=21)\end{array}$ & $\begin{array}{l}\text { Overall } \\
(n=41)\end{array}$ \\
\hline $\begin{array}{l}\text { Age, years, mean } \\
\text { (SD) }\end{array}$ & $50(12.7)$ & 48 (10.9) & 49 (11.7) \\
\hline \multicolumn{4}{|l|}{$\operatorname{Sex}(n, \%)$} \\
\hline Male (n, \%) & 19 (95.0) & $21(100)$ & $40(97.6)$ \\
\hline Female (n, \%) & $1(5.0)$ & 0 & $1(2.4)$ \\
\hline $\begin{array}{l}\text { Body weight, kg, } \\
\text { mean (SD) }\end{array}$ & $97.6(22.7)$ & $97.4(19.2)$ & $97.5(20.7)$ \\
\hline $\begin{array}{l}\text { Body mass index, } \\
\mathrm{kg} / \mathrm{m}^{2} \text {, mean (SD) }\end{array}$ & $32.0(6.2)$ & $31.7(5.8)$ & $31.9(5.9)$ \\
\hline \multicolumn{4}{|l|}{ Race (n, \%) } \\
\hline Asian & $3(15.0)$ & $1(4.8)$ & $4(9.8)$ \\
\hline $\begin{array}{l}\text { Black or African } \\
\text { American }\end{array}$ & $3(15.0)$ & 3 (14.3) & $6(14.6)$ \\
\hline White & $14(70.0)$ & $17(81.0)$ & $31(75.6)$ \\
\hline \multicolumn{4}{|l|}{ Ethnicity (n, \%) } \\
\hline Hispanic or Latino & $8(40.0)$ & $11(52.4)$ & 19 (46.3) \\
\hline $\begin{array}{l}\text { Not Hispanic or } \\
\text { Latino }\end{array}$ & $12(60.0)$ & $10(47.6)$ & $22(53.7)$ \\
\hline $\begin{array}{l}\text { Serum urate, mg/ } \\
\mathrm{dL}, \text { mean }(\mathrm{SD})\end{array}$ & $9.0(1.05)$ & $9.2(1.30)$ & $9.1(1.17)$ \\
\hline
\end{tabular}

The demographic and baseline characteristics of the subjects are summarised in table 1 . Forty subjects were male and the majority $(75.6 \%)$ were white. Mean age, weight and body mass index (BMI) were similar between the cohorts. The overall mean (SD) sUA at baseline was 9.1 (1.17) $\mathrm{mg} / \mathrm{dL}$.

\section{Pharmacodynamics}

The time course of mean per cent change in sUA from baseline (time matched) is shown in figure 2 . The mean time to $\mathrm{E}_{\max }$ ranged from 7 to 12 hours postdose for each treatment. Verinurad $(2.5-20 \mathrm{mg})$ combined with allopurinol $300 \mathrm{mg}$ once daily decreased $\mathrm{E}_{\max }$ in a dose-dependent manner (figure 3). Least-squares mean $\mathrm{E}_{\max }$ was $47 \%, 59 \%, 60 \%, 67 \%, 68 \%$ and $74 \%$, respectively, for verinurad doses of 2.5, 5, 7.5, 10, 15 and $20 \mathrm{mg}$ in combination with allopurinol $300 \mathrm{mg}$ once daily, versus $40 \%, 54 \%$ and $54 \%$ for allopurinol $300 \mathrm{mg}$ once daily, allopurinol $600 \mathrm{mg}$ once daily and allopurinol $300 \mathrm{mg}$ twice daily alone. Verinurad at all doses combined with allopurinol $300 \mathrm{mg}$ once daily produced significantly greater $\mathrm{E}_{\max }$ than allopurinol $300 \mathrm{mg}$ alone, while verinurad doses $\geq 5 \mathrm{mg}$ combined with allopurinol $300 \mathrm{mg}$ once daily produced greater $\mathrm{E}_{\max }$ than allopurinol $600 \mathrm{mg}$ once daily or $300 \mathrm{mg}$ twice daily alone $(\mathrm{P}<0.05$, all comparisons within each cohort). Allopurinol $600 \mathrm{mg}$ once daily was equivalent to allopurinol 300 twice daily in $\mathrm{E}_{\max }$ (figure 3).

Because of difficulty with the storage conditions of the urinary PD samples, urinary uric acid PD parameters 
Cohort 1

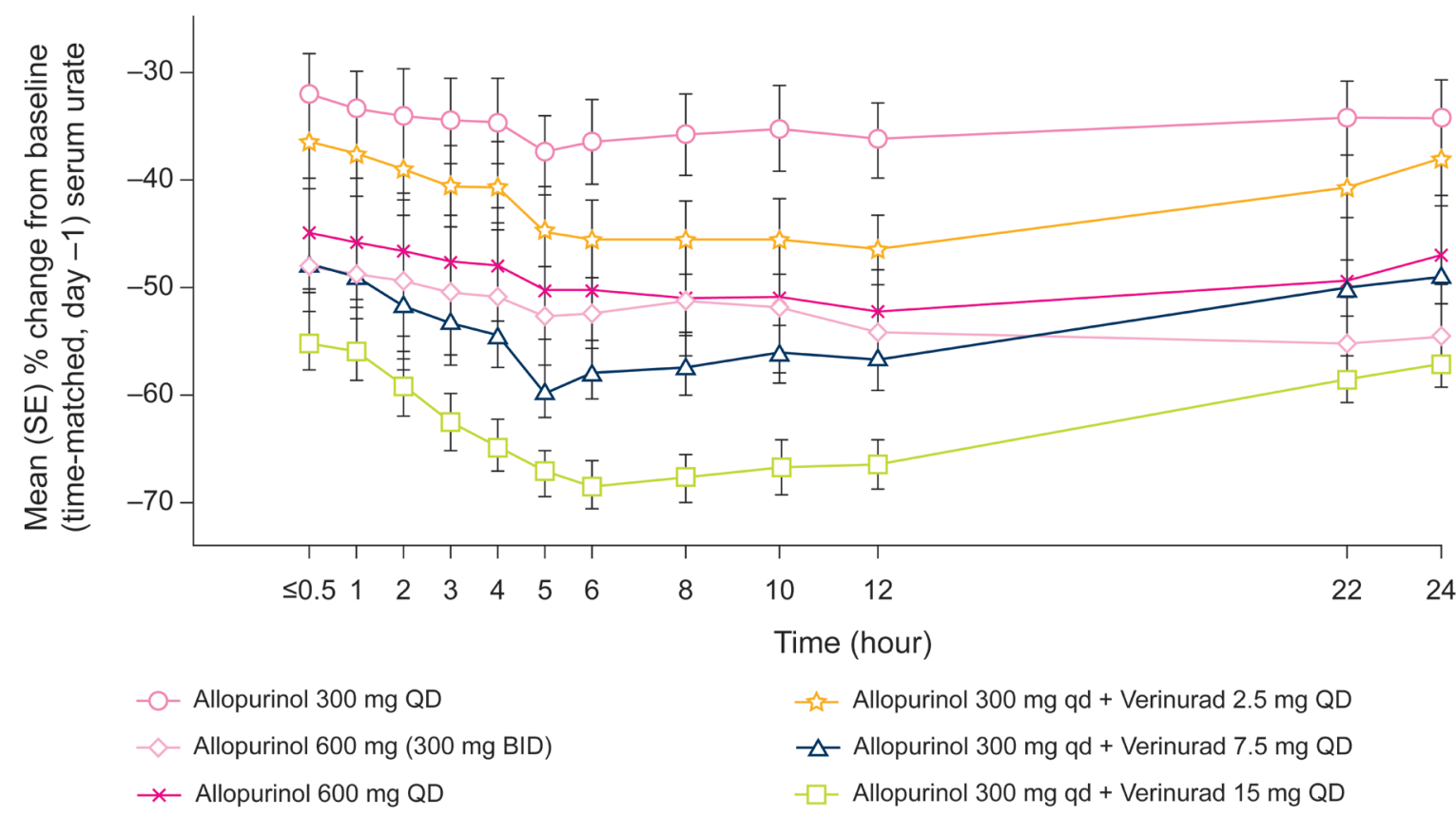

Cohort 2

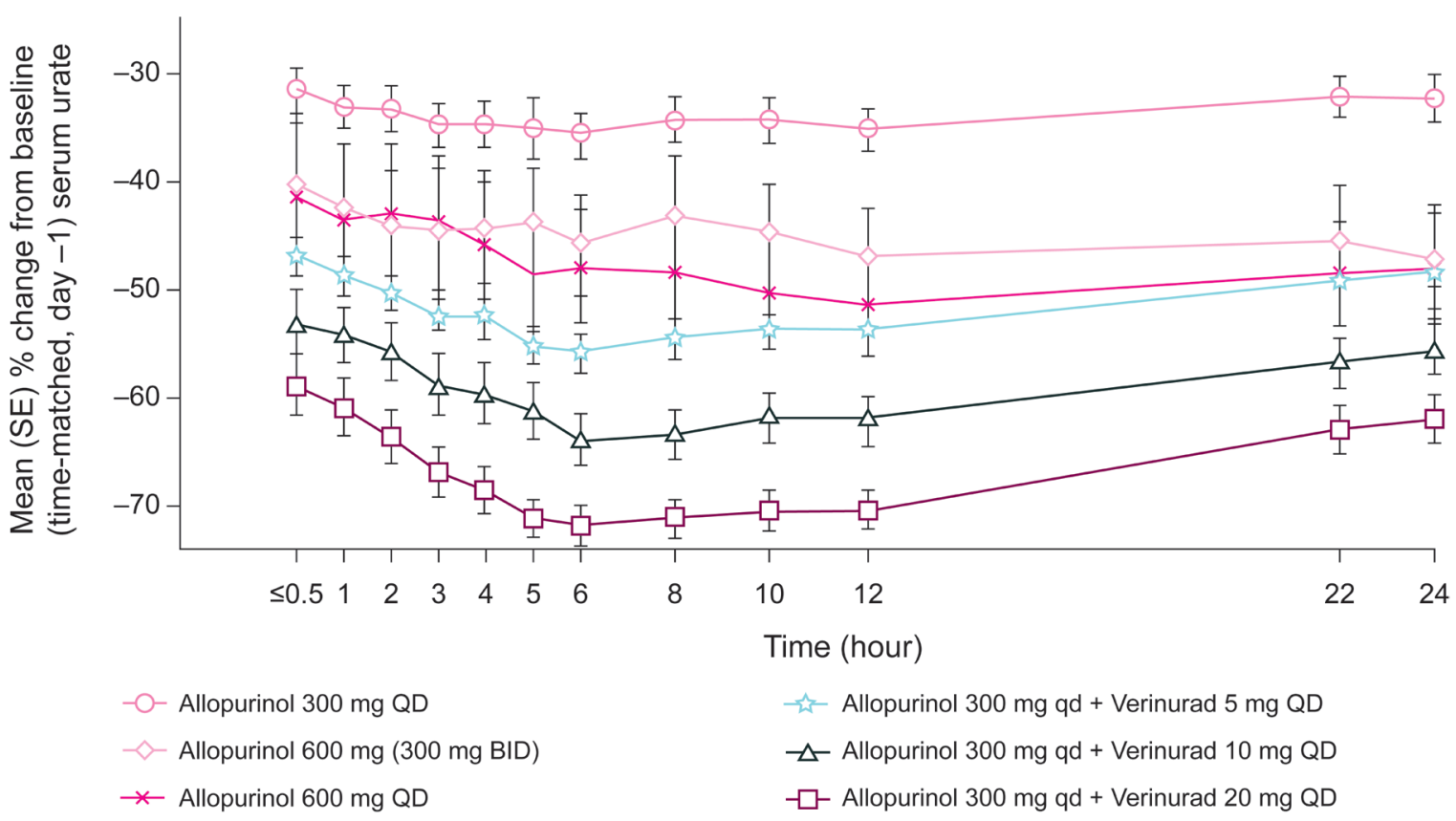

Figure 2 Mean (SE) per cent change from baseline in serum urate $(\mathrm{mg} / \mathrm{dL})$ following once-daily oral administration of varying verinurad doses in combination with allopurinol $300 \mathrm{mg}$ once daily versus allopurinol $300 \mathrm{mg}$ once daily, $300 \mathrm{mg}$ twice daily or $600 \mathrm{mg}$ once daily alone.

could not be determined accurately and are therefore not reported.

\section{Pharmacokinetics}

Mean plasma concentration profiles of verinurad in combination with allopurinol are shown in figure 1 in the online Supplementary file 2. The median $\mathrm{T}_{\max }$ of verinurad ranged from 3.00 to 3.97 hours and the mean $\mathrm{t}_{1 / 2}$ ranged from 9.4 to 20.0 hours postdose for varying doses of verinurad in combination with allopurinol $300 \mathrm{mg}$ once daily (table 2 ). Increases in verinurad $\mathrm{C}_{\max }$ and AUC were dose dependent (table 2; figure 1 in the online Supplementary file 2). 




Figure 3 Maximum mean (SE) per cent change in serum urate from baseline $\left(E_{\max }\right)$ following once-daily oral administration of varying verinurad doses in combination with allopurinol $300 \mathrm{mg}$ versus allopurinol $300 \mathrm{mg}$ once daily, $600 \mathrm{mg}$ once daily or $300 \mathrm{mg}$ twice daily alone (allopurinol data pooled across cohorts).

Verinurad did not affect the plasma PK of allopurinol, but dose dependently reduced oxypurinol $\mathrm{C}_{\max }$ by $19.0 \%-$ $32.4 \%$ and $\mathrm{AUC}_{\text {last }}$ by $20.8 \%-39.2 \%$ (table 3 ). Allopurinol administered as a single $600 \mathrm{mg}$ dose produced comparable AUCs to divided $300 \mathrm{mg}$ doses for allopurinol (least-squares geometric mean ratios (90\% CIs): 204 (162 to 257) for $\mathrm{C}_{\max }$ and 128 (101 to 162) for $\mathrm{AUC}_{0-24}$ ) and oxypurinol (122 (103 to 146) and 115 (93.0 to 143), respectively).

Urinary drug concentration measurements were not affected by the storage conditions. Verinurad $\mathrm{Ae}_{0-24}$ increased with verinurad dose in combination with allopurinol $300 \mathrm{mg}$ once daily, from $17.8 \mu \mathrm{g}$ at $2.5 \mathrm{mg}$ verinurad to $165 \mu \mathrm{g}$ at $20 \mathrm{mg}$ verinurad. Verinurad $\mathrm{fe}_{0-24}$ ranged from $0.63 \%$ to $0.87 \%$ (table 2) and $\mathrm{CL}_{\mathrm{R} 0-24}$ from 8 to $11 \mathrm{~mL} / \mathrm{min}$.

Allopurinol $\mathrm{Ae}_{0-24}$ and $\mathrm{CL}_{\mathrm{R} 0-24}$ were generally unchanged by verinurad at any dose, while oxypurinol Ae increased by $5 \%-29 \%$ and $\mathrm{CL}_{\mathrm{R}}$ by $32 \%-101 \%$ with increasing verinurad doses relative to allopurinol $300 \mathrm{mg}$ once daily alone (table 3 ).

\section{Safety}

Twelve subjects reported 23 treatment-emergent AEs (TEAEs). The most common individual TEAEs (in $>5 \%$ of subjects) in the combined cohorts were upper

Table 2 Plasma and urine pharmacokinetics of verinurad following once-daily oral administration of varying verinurad doses in combination with allopurinol $300 \mathrm{mg}$ once daily (geometric means, $95 \% \mathrm{Cls}$ )

\begin{tabular}{|c|c|c|c|c|c|}
\hline Verinurad (mg) & $C_{\max }(\mathrm{ng} / \mathrm{mL})$ & $\begin{array}{l}\text { AUC }_{0-24} \\
\text { (ng·hour/mL) }\end{array}$ & $\mathbf{T}_{\max }$ (hour) & $t_{1 / 2}$ (hour) $^{*}$ & $\mathrm{fe}_{0-24}(\%)$ \\
\hline 2.5 & 4.28 (3.33-5.49) & $33.9(25.4-45.3)$ & $3.83(0.967-9.83)$ & 9.40 (6.97-12.7) & $0.711(0.462-1.09)$ \\
\hline 7.5 & $11.2(9.07-13.7)$ & $92.0(74.8-113)$ & 3.00 (1.00-9.97) & $12.0(8.33-17.4)$ & $0.679(0.500-0.920)$ \\
\hline 10 & $15.3(13.1-18.0)$ & $145(125-167)$ & $3.43(1.50-6.02)$ & $20.0(12.2-32.8)$ & 0.868 (0.669-1.13) \\
\hline
\end{tabular}

$\mathrm{T}_{\max }$ values are presented as median (range).

${ }^{*}$ Terminal $t_{1 / 2}$ values were calculated from a period of less than twofold of the calculated $t_{1 / 2}$ value in more than half the subjects in the same dose group.

$\mathrm{AUC}_{0-24}$, area under the plasma concentration-time curve from time zero to 24 hours postdose; $\mathrm{C}_{\max }$, maximum observed concentration; $\mathrm{fe}_{0-24}$, fraction excreted in urine as unchanged drug or metabolite; $\mathrm{T}_{\max }$, time of maximum observed plasma concentration. 


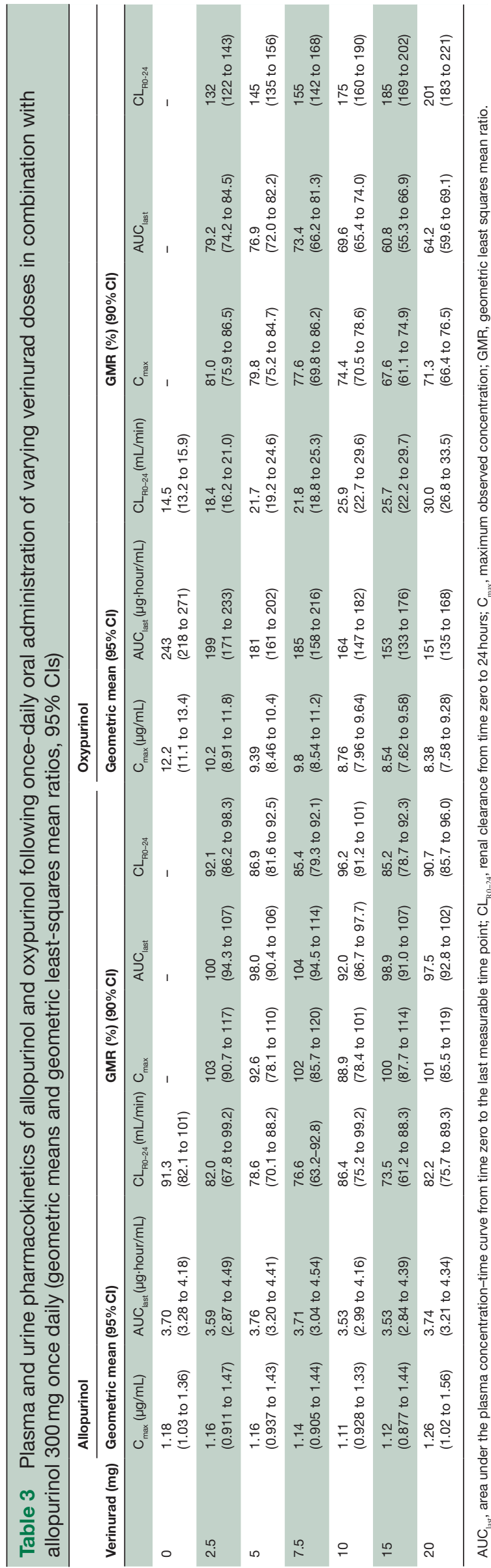

respiratory tract infection ( $\mathrm{n}=4$ subjects, $9.8 \%)$ and headache $(\mathrm{n}=3,7.3 \%)$.

No TEAEs led to study withdrawal. During follow-up, one subject experienced a serious $\mathrm{AE}$ of aspiration pneumonia and acute renal failure that was attributed to dehydration following alcohol inebriation and vomiting.

No clinically meaningful changes in laboratory values or vital signs were observed, including no cases of $\mathrm{sCr}$ elevation $\geq 1.5 \times$ baseline.

\section{DISCUSSION}

Verinurad is a potent, selective inhibitor of the URAT1 transporter in clinical development for the treatment of gout and asymptomatic hyperuricaemia. In this phase IIa study of 41 subjects with gout and baseline sUA $\geq 8 \mathrm{mg} / \mathrm{dL}$, verinurad $(2.5-20 \mathrm{mg})$ in combination with allopurinol $300 \mathrm{mg}$ reduced sUA in a dose-dependent manner. Verinurad at doses $\geq 2.5 \mathrm{mg}$ in combination with allopurinol $300 \mathrm{mg}$ once daily produced greater sUA lowering than allopurinol $300 \mathrm{mg}$ once daily alone, while verinurad $\geq 5 \mathrm{mg}$ in combination with allopurinol $300 \mathrm{mg}$ once daily lowered sUA more than allopurinol $600 \mathrm{mg}$ alone (once daily or twice daily), thereby demonstrating a greater PD effect for combination therapy than allopurinol dose escalation. These observations are consistent with phase Ib studies of lesinurad (another URAT1 inhibitor) in combination with an XOI in patients with gout, where combination therapy also produced greater sUA lowering than an increased dose of XOI. ${ }^{28}$

The current study also compared the plasma PD and PK of allopurinol $600 \mathrm{mg}$ when given once daily or twice daily. The AUC and sUA-lowering efficacy of allopurinol were comparable for once daily and twice daily administration, suggesting that the extent of sUA lowering is attributable to AUC rather than $\mathrm{C}_{\max }$. This short-term study adds to the limited data on allopurinol dosing and indicates that, based on PD effects, it may not be necessary to divide daily doses above $300 \mathrm{mg}$, as currently recommended in the prescribing information for allopurinol.

Urinary PD parameters were not assessed in this study due to improper storage conditions for urinary uric acid. However, the effects of verinurad on urinary excretion of uric acid have been characterised elsewhere: in a phase I, drug-drug interaction study in human volunteers and in a phase IIa, open-label study of verinurad combined with febuxostat in subjects with gout, the verinurad and XOI combination was associated with urinary uric acid excretion levels at or below baseline levels, ${ }^{21} 29$ in support of the contention that XOI-mediated reductions in urinary uric acid will offset elevations in urinary uric acid associated with uricosuric agents.

Verinurad plasma exposures increased dose proportionally with increasing doses. Verinurad did not influence the PK of allopurinol (in contrast with Hall et $a l^{24}$ ), but did lower oxypurinol plasma exposure, most likely via inhibition of URAT1 and increased urinary oxypurinol excretion. ${ }^{30}$ It is notable that lesinurad and 
benzbromarone (other URAT inhibitors) in combination with allopurinol also lower oxypurinol plasma exposure. ${ }^{31}{ }^{32}$ Despite the effect of verinurad on oxypurinol PK, it should be emphasised that the verinurad and allopurinol combination produced significantly greater sUA lowering than allopurinol alone.

All dose combinations of verinurad and allopurinol were generally well tolerated, with no serious AEs or renal-related events and no clinically meaningful changes in laboratory evaluations during treatment.

Limitations of the study include the short study duration, the inclusion of subjects with high mean sUA levels $(>9 \mathrm{mg} / \mathrm{dL})$ at baseline and the failure to obtain urinary uric acid data. Strengths of the study include the frequent blood samplings that increased the reliability of the PD and PK analyses, the inclusion of subjects with gout to ensure clinical relevance and the randomisation design that eliminated sequence effects.

In conclusion, oral verinurad at the doses studied $(2.5-20 \mathrm{mg})$ in combination with allopurinol $300 \mathrm{mg}$ once daily produced significantly greater sUA lowering than allopurinol $300 \mathrm{mg}$ once daily alone in subjects with gout. Verinurad at doses $\geq 5 \mathrm{mg}$ combined with allopurinol $300 \mathrm{mg}$ once daily also produced significantly greater sUA lowering than allopurinol $600 \mathrm{mg}$ alone, indicative of greater efficacy for this combination than for allopurinol dose escalation. All dose combinations of verinurad and allopurinol were generally safe and well tolerated, with no instances of sCr elevation. These data support continued investigation of oral verinurad in a dual-mechanism approach to lowering sUA.

Acknowledgements Editorial support for this manuscript was provided by Bill Wolvey of PAREXEL, which was funded by AstraZeneca.

Contributors All the authors contributed to the acquisition, analysis, interpretation of data for the work, drafting the work or revising it critically for important intellectual content and final approval of the version to be published. JNM, JH and MG were involved in the conception and design of the work

Funding Funding for this study was provided by Ardea Biosciences/ AstraZeneca.

Competing interests RF received a clinical study grant from Ardea Biosciences. PW is a full-time employee of Anaheim Clinical Trials. JNM, XY, LH, SV, JH, SL and ZS are/were full-time employees of Ardea Biosciences, a member of the AstraZeneca Group. MG is a full-time employee of AstraZeneca. MHI reports no conflict of interest.

Patient consent Obtained.

Ethics approval Schulman Associates IRB, Cincinnati, Ohio, USA.

Provenance and peer review Not commissioned; externally peer reviewed.

Data sharing statement De-identified patient data from this study are made available for scientific research on a case by case basis through AstraZeneca's Data Request Portal: https://astrazenecagroup-dt.pharmacm.com//DT/Home/ Index/

Open Access This is an Open Access article distributed in accordance with the Creative Commons Attribution Non Commercial (CC BY-NC 4.0) license, which permits others to distribute, remix, adapt, build upon this work non-commercially, and license their derivative works on different terms, provided the original work is properly cited and the use is non-commercial. See: http://creativecommons.org/ licenses/by-nc/4.0/

(C) Article author(s) (or their employer(s) unless otherwise stated in the text of the article) 2018. All rights reserved. No commercial use is permitted unless otherwise expressly granted.

\section{REFERENCES}

1. Bardin T, Richette P. Definition of hyperuricemia and gouty conditions. Curr Opin Rheumatol 2014;26:186-91.

2. Perez-Ruiz F, Dalbeth N, Bardin T. A review of uric acid, crystal deposition disease, and gout. Adv Ther 2015;32:31-41.

3. Rees F, Hui M, Doherty M. Optimizing current treatment of gout. Nat Rev Rheumatol 2014;10:271-83.

4. Doherty M, Jansen TL, Nuki G, et al. Gout: why is this curable disease so seldom cured? Ann Rheum Dis 2012;71:1765-70.

5. Richette P, Doherty M, Pascual E, et al. 2016 updated EULAR evidence-based recommendations for the management of gout. Ann Rheum Dis 2017;76:29-42.

6. Sundy JS, Ganson NJ, Kelly SJ, et al. Pharmacokinetics and pharmacodynamics of intravenous PEGylated recombinant mammalian urate oxidase in patients with refractory gout. Arthritis Rheum 2007:56:1021-8.

7. Khanna D, Fitzgerald JD, Khanna PP, et al. 2012 American College of Rheumatology guidelines for management of gout. Part 1: systematic nonpharmacologic and pharmacologic therapeutic approaches to hyperuricemia. Arthritis Care Res 2012;64:1431-46.

8. Stamp LK, Taylor WJ, Jones PB, et al. Starting dose is a risk factor for allopurinol hypersensitivity syndrome: a proposed safe starting dose of allopurinol. Arthritis Rheum 2012;64:2529-36.

9. Singh JA, Akhras KS, Shiozawa A. Comparative effectiveness of urate lowering with febuxostat versus allopurinol in gout: analyses from large U.S. managed care cohort. Arthritis Res Ther 2015; $17: 120$

10. Becker MA, Fitz-Patrick D, Choi HK, et al. An open-label, 6-month study of allopurinol safety in gout: the LASSO study. Semin Arthritis Rheum 2015;45:174-83.

11. Bardin T, Keenan RT, Khanna PP, et al. Lesinurad in combination with allopurinol: a randomised, double-blind, placebo-controlled study in patients with gout with inadequate response to standard of care (the multinational CLEAR 2 study). Ann Rheum Dis 2017;76:811-20.

12. Dalbeth N, Jones G, Terkeltaub R, et al. Lesinurad, a selective uric acid reabsorption inhibitor, in combination with febuxostat in patients with tophaceous gout: findings of a phase III clinical trial. Arthritis Rheumatol 2017;69:1903-13.

13. Saag KG, Fitz-Patrick D, Kopicko J, et al. Lesinurad combined with allopurinol: a randomized, double-blind, placebo-controlled study in gout patients with an inadequate response to standard-of-care allopurinol (a US-Based Study). Arthritis Rheumatol 2017;69:203-12.

14. Pascual E, Andrés M, Vela P. Gout treatment: should we aim for rapid crystal dissolution? Ann Rheum Dis 2013;72:635-7.

15. Perez-Ruiz F, Calabozo M, Pijoan JI, et al. Effect of urate-lowering therapy on the velocity of size reduction of tophi in chronic gout. Arthritis Rheum 2002;47:356-60.

16. Perez-Ruiz F. Treating to target: a strategy to cure gout. Rheumatology 2009;48(Suppl 2):ii9-14.

17. Shiozawa A, Buysman EK, Korrer S. Serum uric acid levels and the risk of flares among gout patients in a US managed care setting. Curr Med Res Opin 2017;33:117-24.

18. Terkeltaub R, Perez-Ruiz F, Kopicko J, et al. The safety and efficacy of lower serum urate levels: a pooled analysis of gout subjects receiving lesinurad and xanthine oxidase inhibitors. Arthritis Rheumatol 2015;67(Suppl 10). Abstract 2354.

19. Tan PK, Liu S, Gunic E, et al. Discovery and characterization of verinurad, a potent and specific inhibitor of URAT1 for the treatment of hyperuricemia and gout. Sci Rep 2017;7:665.

20. Gillen M, Miner JN, Valdez S. Pharmacokinetics, pharmacodynamics, and tolerability of verinurad, a selective uric acid reabsorption inhibitor, in healthy Japanese male subjects. Arthritis Rheumatol 2016:68(Suppl 10):1-4550. Abstract 193.

21. VanderLugt J, Gillen M, Yang X, et al. Pharmacokinetics, pharmacodynamics, and tolerability of concomitant multiple dose administration of verinurad (RDEA3170) and febuxostat in healthy adult male subjects. Arthritis Rheumatol 2016;68(Suppl 10):1-4550. Abstract 191.

22. Shen Z, Gillen M, Miner JN, et al. Pharmacokinetics, pharmacodynamics, and tolerability of verinurad, a selective uric acid reabsorption inhibitor, in healthy adult male subjects. Drug Des Devel Ther 2017;11:2077-86.

23. Goldfarb DS, MacDonald PA, Hunt B, et al. Febuxostat in gout: serum urate response in uric acid overproducers and underexcretors. J Rheumatol 2011;38:1385-9.

24. Hall J, Gillen M, Liu S. Pharmacokinetics, pharmacodynamics, and tolerability of concomitant multiple dose administration of verinurad (RDEA3170) and allopurinol in adult male subjects with gout. Arthritis Rheumatol 2016;68(Suppl 10). Abstract 194. 
25. Lee C, Yang C, Shah V, et al. Metabolism and disposition of verinurad, a uric acid reabsorption inhibitor, in humans. Drug Metab Dispos. 2018. In press.

26. Wallace SL, Robinson H, Masi AT, et al. Preliminary criteria for the classification of the acute arthritis of primary gout. Arthritis Rheum 1977;20:895-900.

27. Woodworth T, Furst DE, Alten R, et al. Standardizing assessment and reporting of adverse effects in rheumatology clinical trials II: the Rheumatology Common Toxicity Criteria v.2.0. J Rheumatol 2007:34:1401-14.

28. Fleischmann R, Kerr B, Yeh LT, et al. RDEA594-111 Study Group. Pharmacodynamic, pharmacokinetic and tolerability evaluation of concomitant administration of lesinurad and febuxostat in gout patients with hyperuricaemia. Rheumatology 2014;53:2167-74.
29. Fleischmann R, Winkle P, Hall J. Pharmacodynamic effects and safety of verinurad in combination with febuxostat versus febuxostat alone in adults with gout: a phase 2a, open-label study. Arthritis Rheumatol 2016;68(suppl 10). Abstract 197.

30 Iwanaga T, Kobayashi D, Hirayama M, et al. Involvement of uric acid transporter in increased renal clearance of the xanthine oxidase inhibitor oxypurinol induced by a uricosuric agent, benzbromarone. Drug Metab Dispos 2005;33:1791-5.

31 Müller FO, Schall R, Groenewoud G, et al. The effect of benzbromarone on allopurinol/oxypurinol kinetics in patients with gout. Eur J Clin Pharmacol 1993;44:69-72.

32 Perez-Ruiz F, Sundy JS, Miner JN, et al. Lesinurad in combination with allopurinol: results of a phase 2 , randomised, double-blind study in patients with gout with an inadequate response to allopurinol. Ann Rheum Dis 2016;75:1074-80. 